\title{
A Structure Analysis of English Argumentative Writings Written by Chinese and Korean EFL Learners
}

\author{
Cui Zheng ${ }^{1}$ \\ ${ }^{1}$ School of International Exchange, Shandong Normal University, Jinan, China \\ Correspondence: Cui Zheng, School of Internatoinal Exchange, Shandong Normal University, 250014, 88 East \\ Wenhua Road, Lixia District, Jinan, Shandong, China. Tel: 86-531-86182860. E-mail: \\ zhengcui001ruth@163.com
}

Received: May 31, 2013 Accepted: June 20, 2013 Online Published: August 15, 2013

doi:10.5539/elt.v6n9p67 URL: http://dx.doi.org/10.5539/elt.v6n9p67

\begin{abstract}
This study employed Kamimura and Oi (1996)'s classification of the organizational patterns of the argumentative essay structure: Thesis Statement (TS), Background Information (BI), Reservation (R), Hesitation (H), Rational Appeals (RA), Affective Appeals (AA) and Conclusion (C). 178 essays, 84 written by Chinese EFL learners, 84 written by Korean EFL learners, and 10 written by English native speakers, were coded and analyzed via NVivo. The results show that Chinese and Korean EFL learners prefer the direct deductive expressions in their English argumentative writings, which is different from Kaplan's (1966) findings. No significant difference exists in the essay structure among Chinese and Korean EFL writers' writing and the English native speakers' writings. The only difference lies in the contents of the rational and affective appeals, which are still strongly influenced by the cultural and social background. The results indicate that Chinese and Korean EFL writers, especially most of the university students are able to handle the structure of English argumentative writings with plenty of writing practice and teachers' instruction.
\end{abstract}

Keywords: organizational patterns, argumentative essays, Chinese and Korean EFL learners, deductive expressions

\section{Introduction}

The controversy of rhetoric between Asian and western world exist for a long time. To be specific, the writing style of Asians is usually considered as indirect and inductive, while the writing style of American people is considered as direct and deductive. Thus the question arises: what will happen if Asian EFL learners, i.e. Chinese and Korean EFL learners write in English? Will they still follow their own indirect and inductive writing style or will they become more direct and deductive? This paper thus focuses on the structure analysis of English argumentative writings written by Chinese and Korean EFL learners and tries to investigate whether there is any structure difference among Chinese and Korean EFL learners and English native speakers as well.

\section{Literuature Review}

Kaplan (1966) analyzed the different cultural thought patterns and their influence for L2 writers when they write in English. He pointed out "the teaching of composition to foreign students does differ from the teaching of composition to American students", because "the cultural differences in the nature of rhetoric supple the key to the difference in teaching approach" (p. 1). The famous diagram Kaplan summarized is as below. According to him, English native speakers' essays follow a linear development while some oriental writing is featured by an approach called indirection. Oriental means specifically Chinese and Korean, based on what Kaplan explained. The questions here are: 1) Is the oriental writing really indirect? 2) Does Chinese and Korean EFL writers have the same indirect writing style? 

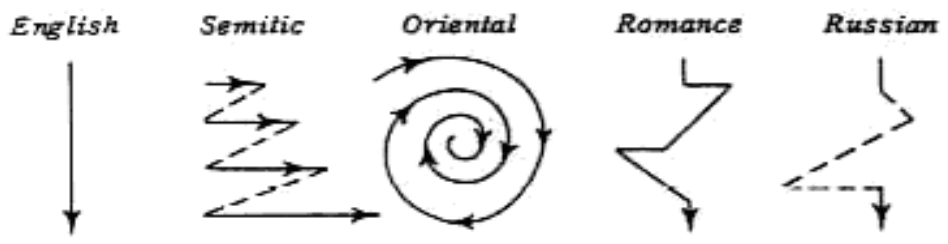

Figure 1. Diagram on cross-cultural differences in paragraph organization in Kaplan's (1966, p. 11) study on cultural thought in intercultural education

Kaplan's theory came into existence almost fifty years ago. Since then, numerous studies were there focusing on the cultural influence on the second language writing. One of the recent studies (Liu \& Furneaux, 2013), reviewed the on-going debates on Kaplan's theory. Liu and Furneaux (2013) claimed that one focal argument is about directness and indirectness of English and Chinese writing. Some researchers still believe that Chinese English learners' writing is indirect (e.g. Cai, 1993; Hinds, 1990; Matalene, 1985). Matalene (1985) described his own English teaching experiences in China and compared the cultural differences between China and America in many ways. One difference he mentioned is that "the linguistic and social tendencies toward indirection are naturally reflected in the ways Chinese writers deal with topics and present their ideas" (p. 802). Cai (1993) also claimed that one strategy Chinese ESL learners use is the "avoidance of self-expression, and the explicit preference for indirectness" (p. 10). However, some more recent studies argued that Chinese ESL learners may also prefer the direct expression when they try to express in English. For instance, Yang and Cahill (2008) found that Chinese students, like their American counterparts, prefer directness in text and paragraph organization, although American students tend to be more direct in paragraph organization. Chien (2011) conducted an empirical study and found out that the majority Chinese students in his experiment in Taiwan used a direct approach for both of their Chinese and English expository compositions.

There are also some rhetoric studies about Korean language. Connor (1996) reviewed the related research of Eggington (1987). Eggington's study shows that Korean texts are characterized by indirectness and nonlinear development, which is called four-part pattern, ki-sung-chon-kyul, the same with Chinese qi-cheng-zhuan-he style (Chen, 2007; Shin, 2007). Choi (1988) studied the argumentative text structure of native English speakers and Korean English learners and found the structures of their essays were quite different.

So all in all, there is no exact answer to the question whether the writing of Chinese and Korean EFL writers is direct or indirect in terms of the essay structure. To be further, it is still in wonder whether Chinese and Korean EFL writers have the same indirect writing style.

\section{Research Methods}

\subsection{Research Question}

This study is intended to analyze and compare the English essay structure written by Chinese and Korean EFL learners and English native writers in order to check out whether they have different rhetorical structures among Chinese and Korean EFL learners and English native writers as well.

\subsection{Subjects}

84 Chinese university students, 84 Korean university students and 10 English native speakers were asked to write an argumentative essay within 30 minutes. The essay prompt was taken from the TOEFL iBT's independent writing topics for Asian test takers. The title is "Do you agree or disagree with the following statement: 'Always telling the truth is the most important consideration in any relationship'?" Then, a total number of 178 essays were collected for the structure analysis, 84 essays written by Chinese EFL learners (CE), 84 essays written by Korean EFL learners (KE) and 10 essays written by English native writers (EE).

\subsection{Research Design}

This study employs Kamimura and Oi (1996)'s classification of the organizational patterns of argumentative essay structure. They are (1) Thesis Statement (TS), (2) Background Information (BI), (3) Reservation (R), (4) Hesitation (H), (5) Rational Appeals (RA), (6) Affective Appeals (AA) and (7) Conclusion (C). Thesis statement is usually a single sentence which presents the writer's opinion. Background information refers to the 
introductory comments concerning the topic/title, without any clear opinion of writers. Reservation refers to the sentences in which the writer recognizes the given topic is a controversial issue and shows his/her understanding to the counter opinion to his/hers. Reservation indicates whether the writer prefer a linear or circular way of thinking. Usually the more reservation, the more circular the writer's thinking method is. Hesitation means the writer need time to decide which side to support. Rational appeals are the logical reasoning the writer uses to persuade the readers, while affective appeals are these specific examples the writer uses to illustrate his or her opinions. Conclusion is the summary of the writer's opinion.

From the location of thesis statement, it is easy to identify whether an essay is deductive or inductive. Generally speaking, if the location of the thesis statement is at the beginning of the essay, the essay is more deductive than inductive. From background information frequency, we can see whether the writer likes direct way or indirect way to state his/her opinion. If the background information is depicted a lot, there may be a clue that the writer likes indirect way to express him or herself. From the proportion of rational appeals and affective appeals, we can see whether the writer prefer logical explanation or prefer the exact examples to support his/her opinion; from the hesitation part, we can see whether the writer has a clear opinion; from the reservation description, writer's thinking method can be implied, whether it is linear or circular; conclusion part indicates whether the author can write a complete essay or not.

Two coders worked together and coded all these seven structural parts of each essay with the help of NVivo, the software for qualitative study. One coded essay example is shown here.

\section{CE (24):}

It is Unnecessary to Tell the Truth in Any Circumstance. In some special situations we'd like to tell the truth and we prefer the people who always telling the truth. (RE) However, it is unnecessary to tell the truth in any relationship, such as the relationship of relatives and lover. (TS)

We often read such article or story: when two lovers run into unexpected danger, for example, come across an fierce tiger, often the boy or the man of the lovers pretend to run away and tell the girl or the woman that he is so sorry to look after her. The female role often feel heart-broken. Actually, the male role tell a lie. Because tiger attack the moving object. He leave the danger to himself and save his lover. This is the true love. (AA)

I remember I have heard a story in which a pilot let his partner jump down from the plane and he stay in the plane. Because he know that the plane is going to explode. His partner think he is a selfish person and is angry with him. Nevertheless, he is a true hero. (AA)

In a word, we needn't to tell the truth in specific occasions. Lies out of kindness are always benefit for the people. So it is unnecessary to tell the truth in any relationship. (C)

\section{Resutls and Discussions}

Table 1 shows a frequency comparison of each part in CE, KE and EE. Some indications could be made from it. Almost all the essays written by Chinese and Korean EFL learners have the thesis statement and conclusions, meaning their essays are quite complete and clear. Chinese EFL learners have a larger proportion of background information, meaning they might be more indirect when stating their opinions. Both Chinese and Korean EFL learners use a large number of rational and affective appeals to support their statement, meaning these EFL learners know how to making their essays more convincing using both logical argument and specific examples. Hesitation exists in none of these essays, which echoes the percentage of thesis statement, meaning that all these writers have clear opinions toward the essay prompt. The proportion of reservation is about $30 \%$ to $40 \%$, which means some essays still use some circular ways to express the writers' opinions instead of single linear ways. One important point is that there is no obvious difference in the structure patterns among $\mathrm{CE}, \mathrm{KE}$ and $\mathrm{EE}$.

Table 1. Comparison of structure patterns among CE, KE and EE

\begin{tabular}{lllllll}
\hline Organizational pattern & \multicolumn{2}{l}{ CE (84) } & \multicolumn{2}{l}{ KE (84) } & \multicolumn{2}{l}{ EE (10) } \\
\hline Thesis Statement & 83 & $99 \%$ & 80 & $95 \%$ & 7 & $70 \%$ \\
Background Information & 36 & $43 \%$ & 21 & $25 \%$ & 2 & $20 \%$ \\
Rational Appeals & 75 & $89 \%$ & 78 & $93 \%$ & 7 & $70 \%$ \\
Affective Appeals & 56 & $67 \%$ & 53 & $63 \%$ & 10 & $100 \%$ \\
Hesitation & 0 & $0 \%$ & 0 & $0 \%$ & 0 & $0 \%$ \\
Reservation & 26 & $31 \%$ & 37 & $44 \%$ & 4 & $40 \%$ \\
Conclusion & 78 & $93 \%$ & 77 & $92 \%$ & 7 & $70 \%$ \\
\hline
\end{tabular}




\subsection{Location of Thesis Statement}

Table 2 shows the location of the thesis statement. Out of the whole 168 essays written by EFL learners, only 5 essays fail to state their opinion clearly. It means that almost all EFL learners know thesis statement is one necessary part in the essay structure. Most writers including the English native speakers locate their statement in the beginning of the essay; only a small proportion of statement is located in the middle or at the end of the essays. Locating the thesis statement in the middle of the essay is the least preferred.

Table 2. Comparison of location of the thesis statement

\begin{tabular}{lllllll}
\hline Location & CE & \multicolumn{3}{c}{ KE } & \multicolumn{3}{c}{ EE } \\
\hline Beginning & 70 & $83 \%$ & 61 & $73 \%$ & 7 & $70 \%$ \\
Middle & 5 & $6 \%$ & 4 & $5 \%$ & 0 & $0 \%$ \\
End & 8 & $10 \%$ & 15 & $18 \%$ & 0 & $0 \%$ \\
No TS & 1 & $1 \%$ & 4 & $4 \%$ & 3 & $30 \%$ \\
\hline
\end{tabular}

On the other hand, results in Table 2 indicate there is no clear difference between CE, KE and EE in terms of TS location. As mentioned, most of the writers prefer to state their opinion in the first paragraph of the essay, which means deductive rather than inductive approaches are adopted by most of writers.

\subsection{Proportion of Background Information}

Background information, as mentioned, is about the background introductions which are related with the topic, not the opinions of the writers. Based on the description in Table 1 above and the coding as well, out of 168 essays, 57 essays state the background information before the thesis statement, among which there are $34 \mathrm{CE}$ and $23 \mathrm{KE}$. And among $10 \mathrm{EE}$, only 2 include the BI at the beginning. Due to the size limitation of the essays, it is hard to definitely say $\mathrm{CE}$ learners tend to state their opinions more indirectly than KE learners, but at least to some extent, it might be true. Chinese EFL learners may prefer more background information before state their own opinions. Here is a CE (essay 12) which states background information before writer's opinion.

\section{Communicating}

In our daily life, we are in an complicated situation of contracting. So it need us to deal with it well. But sometimes we are very contraditial when we wonder wheather we should tell the truth to them. (BI)

I think telling the truth will hurt sb if the truth is bad for him/her. (TS) Because people tend to like the best things. You tell the truth, he/she may leave you or ignore you if he/she doesn't believe the truth. (RA)

Communication is an art for people to live well in the social living. So you can feel wheather the truth is important for people. If it has nothing to doing with them, you can lie to them. And they don't has trouble with you. $(\boldsymbol{R} \boldsymbol{A})$

If the truth is important or serious, you should tell them the truth. Because they may think you regard them as good friends. You can receive their respect, and they will be close to you. (RA)

In addition, I think there're good lies if they are good for people, so we should know what it is about, and know how to deal with it. Maybe you lie, but people will understand you finally and they will thank for what you have given. $(\boldsymbol{R} \boldsymbol{A})$

No matter you tell truth or lie, make sure that you are thinking for others, then you will have a good reputation. And people will respect you and get on well with you. (C)

This is a well-organized essay, regardless of the grammar and vocabulary errors in the essay. Instead of stating his opinion directly at the beginning, the writer chose to talk about the social environment first, and then raised the question that in the complicated society, whether we need to tell the truth or not. Followed that is the writer's own opinion, and then the three rational reasons supporting the writer's opinion, with the conclusion in the end. The writer's structure is very clear. The structure problem may lie in the missing of the affective appeals.

\subsection{Rational and Affective Appeals}

A good essay usually should contain both rational and affective appeals to support writer's opinion. No big difference is found between $\mathrm{CE}, \mathrm{KE}$ and $\mathrm{EE}$ in terms of rational and affective appeals based on the Table 1 shown above. But if there is, both of Chinese and Korean EFL writers tend to use more logical explanation 
instead of example illustration than English native writers. However, due to the size limitation, it is hard to validate this statement.

One interesting finding is that when talking about the necessity of telling lies or telling the truth, some Chinese EFL writers mentioned the 'harmony' of the society, such as "We just want to make our life easier and ore harmonious, make the world more beautiful."(CE50), "telling the truth will be the most important element to build the harmony family or make the best friends."(CE35) "If we all did it, I think our society is very harmonious in future."(CE98) "Because we should build up the harmony life and relationship and society." (CE51) Mentioning the harmony of the society should be a good point in the essay, but on the other hand, it shows the social and cultural influence on English learning and writing. Since China is focusing on building the harmonious society, English learners' refection in their writing could be understood.

In terms of the affective appeals, in order to illustrate the negative result of telling lies, both Chinese and Korean EFL writers mention the story of shepherd boy who lies to people about wolves. "A shepherd tells a lie so many time that a wolf appears. Someday a wolf appears in reality but nobody believes. So the shepherd's sheep are eaten."(KE55) or "For the third time, the boy again shouted there came a hungry wolf. But nobody believed what he said and kept busy on their crops. The result, as you guess, is a tragedy that the boy was eaten by the wolf."(CE73). This story indicates that in some aspects, Chinese and Korean have the shared cultural background.

In addition, in order to prove the necessity of 'white lies', both CE and KE EFL writers gave examples about a person who is diagnosed with cancer or some other serious disease. "If someone got cancer, as a doctor, should he tell the truth to the patient? As I see it, the doctor should not tell the truth." (CE104). "For example, suppose that a patient who is diagnosed with a cancer and a doctor thinks he may live six month at most. In this situation, how do you have to tell him about his disease?"(KE91) This phenomenon may also reflect a similar cultural background shared by both Chinese and Korean English learners.

However, some differences between $\mathrm{CE}$ and $\mathrm{KE}$ in the aspect of affective appeals do exist. Some Korean learners gave some examples about people's appearance such as hair style, wearing style etc; while few Chinese learners mention this aspect. Here is one example from KE.

Imagine a situation that a woman changes her hairstyle, but the new style is not suit on her. You are a friend of her, and you also think the new hair style is bad on her. Would you tell the truth to her? Whether you tell her a truth or not, she cannot get back to her old hair style. She already knows that the hairstyle is terrible by herself. (KE91)

\subsection{Reservation}

As mentioned before, reservation refers to the writer's understanding to the counter opinion to his/hers. Reservation usually indicates whether the writer prefer a linear or circular way of thinking. The more reservation, the more circular the writer's thinking method may be. Based on Kaplan's (1966) cultural thought model, both Chinese and Korean belong to the oriental group, which means both of them prefer an indirect and circular way to express their opinions in writing. Table 1 didn't show much difference between $\mathrm{CE}, \mathrm{KE}$ and $\mathrm{EE}$ in terms of reservation usage. But if we compare the frequency of reservation (KE: 44\%; CE: $31 \%$ ), KE writers tend to use more reservations than $\mathrm{CE}$ writers. Here are some examples.

CE:

In some special situations we'd like to tell the truth and we prefer the people who always telling the truth. (RE)However, it is unnecessary to tell the truth in any relationship, such as the relationship of relatives and lover. (CE24)

KE:

1) Always telling the truth is reasonable. (RE) But, telling the lie is situated better.(RA) (KE6)

2) Sometimes, telling a lie is needed. I agree. (RE) Although it is needed, truth is stronger in the end. If those who heard a lie know the truth later, they are really disappointed. (RA) (KE80) 


\subsection{Writers' Opinions}

Table 3. Frequency of writers' opinions

\begin{tabular}{lllllll}
\hline & CE & \multicolumn{3}{l}{ KE } & \multicolumn{2}{c}{ EE } \\
\hline Pro & 32 & $38 \%$ & 19 & $23 \%$ & 3 & $30 \%$ \\
Con & 42 & $50 \%$ & 58 & $69 \%$ & 5 & $50 \%$ \\
Neutral & 10 & $12 \%$ & 7 & $8 \%$ & 2 & $20 \%$ \\
\hline
\end{tabular}

Regardless of the nationality, more writers oppose the statement than to agree with it. And it is also true within $\mathrm{CE}$ and KE, although more Chinese chose to agree with the statement than Korean writers. Based on the investigation on the writers' opinions, it can be quite wildly acknowledged that people from totally different cultures could have the same or similar opinions towards some topics. The only pity is the number of the English native speakers which decreased the validity of the result.

\section{Conclusions}

This study tried to analyze and compare the English essay structure written by Chinese and Korean EFL learners and English native writers and to answer that question: whether they have different rhetorical structures among Chinese and Korean EFL learners and English native writers as well. The study thus analyzed the structure of CE, $\mathrm{KE}$ and EE from seven aspects: thesis Statement, background Information, reservation, hesitation, rational appeals, affective appeals and conclusion with the help of the software NVivo. Based on Kaplan's (1966) cultural thought model, both Chinese and Korean belong to the oriental group, which means they probably share more similarities than differences. Analysis indeed shows they share more similarities, but meanwhile, there is no evident difference between them and EE. Results include 1) Most of both CE, KE and EE writers prefer to state their opinion in the first paragraph, which means deductive approach rather than inductive approach is adopted by most first language and foreign language writers. Hirose (2003) also had the similar finding that a majority of Japanese students employed deductive type organizational patterns in both their Japanese and English writings. 2) No big difference is found between $\mathrm{CE}$ and $\mathrm{KE}$ in the use of rational and affective appeals. However, the rational and affective appeals are strongly influenced by the cultural and social background.

The findings echo with the results of Yang and Cahill (2008), Chein (2011) and Liu and Furneaux (2013). The limitation of this study is the size of the subjects. Due to the size limitations, some findings could not be applied to a larger extent. If more essays written by English native speakers could be used for the comparison, the result must be more convincing. However, the study still shows to some extent that Chinese and Korean EFL learners' writing is not as indirect and inductive as Kaplan (1966), Matalene (1985) and Cai (1993) described before. More and more EFL learners and teachers have realized the different organizational patterns in English essays and have improved a lot when writing in English.

\section{References}

Cai, G. (1993, March). Beyond bad writing: Teaching English composition to Chinese ESL students. Paper presented at the University Composition and Communication Conference, San Diego, CA.

Chen, W-C. (2007). Some literature review on the comparison of the Chinese Qi-Cheng-Zhuan-He writing model and the western problem-solution schema. WHAMPOA-An Interdisciplinary Journal, 52, 137-148.

Chien, S-C. (2011). Discourse organization in high school students' writing and their teachers' writing instruction: the case of Taiwan. Foreign Language Annals, 44(2), 417-435. http://dx.doi.org/10.1111/j.1944-9720.2011.01131.x

Choi, Y. H. (1988). Text structure of Korean speakers' argumentative essays in English. World English, 7(2), 129-142. http://dx.doi.org/10.1111/j.1467-971X.1988.tb00226.x

Conor, U. (1996). Contrastive rhetoric--cross-cultural aspects of second-language writing. Cambridge: Cambridge University Press.

Eggington, W. G. (1987). Written academic discourse in Korean: Implications for effective communication. In U. Connor, \& R. B. Kaplan (Eds.), Writing across languages: Analysis of L2 text (pp. 153-168). Reading, MA: Addison-Wesley.

Hinds, J. (1990). Inductive, deductive, quasi-inductive: Expository writing in Japanese, Korean, Chinese and 
Thai. In U. Connor, \& A. M. Johns (Eds.), Coherence in writing: Research and pedagogical perspectives (pp. 87-110). Alexandria, VA: TESOL.

Hirose, K. (2003). Comparing L1 and L2 organizational patterns in the argumentative writing of Japanese EFL

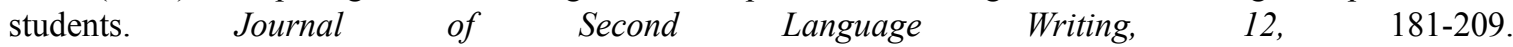
http://dx.doi.org/10.1016/S1060-3743(03)00015-8

Kamimura, T., \& Oi, K. (1996, March). A crosscultural analysis of argumentative strategies in student essays. Paper presented at the Annual Meeting of the Teachers of English to Speakers of Other Languages, Chicago, IL.

Kaplan, R. (1966). Cultural thought patterns in intercultural education. Language Learning, 16, 1-20. http://dx.doi.org/10.1111/j.1467-1770.1966.tb00804.x

Liu, X., \& Furneaux, C. (2013). A multidimensional comparison of discourse organization in English and Chinese university students' argumentative writing. International Journal of Applied Linguistics, 5, 1-23. http://dx.doi.org/10.1111/ijal.12013

Matalene, C. (1985). Contrastive rhetoric: An American writing teacher in China. College English, 47(8), 789-808.

Shin, C-C. (2007). The role of Chinese EFL learners' rhetorical strategy use in relation to their achievement in English writing. English Teaching: Practice and Critique, 6(1), 132-150. http://dx.doi.org/10.4304/jltr.3.6.1061-1070

Yang, L., \& Cahill, D. (2008). The rhetorical organization of Chinese and American students' expository essays: a contrastive rhetoric study. International Journal of English Studies, 8(2), 113-32.

\section{Copyrights}

Copyright for this article is retained by the author(s), with first publication rights granted to the journal.

This is an open-access article distributed under the terms and conditions of the Creative Commons Attribution license (http://creativecommons.org/licenses/by/3.0/). 